\title{
Managing Deep Postanal Space Sepsis via an Intersphincteric Approach: Our Early Experience
}

\author{
Ker-Kan Tan, Dean C. Koh, Charles B. Tsang \\ Division of Colorectal Surgery, University Surgical Cluster, National University Health System, Singapore
}

Purpose: Managing deep postanal (DPA) sepsis often involves multiple procedures over a long time. An intersphincteric approach allows adequate drainage to be performed while tackling the primary pathology at the same sitting. The aim of our study was to evaluate this novel technique in managing DPA sepsis.

Methods: A retrospective review of all patients who underwent this intersphincteric technique in managing DPA sepsis from February 2008 to October 2010 was performed. All surgeries were performed by the same surgeon.

Results: Seventeen patients with a median age of 43 years (range, 32 to 71 years) and comprised of $94.1 \%(\mathrm{n}=16)$ males formed the study group. In all patients, an internal opening in the posterior midline with a tract leading to the deep postanal space was identified. This intersphincteric approach operation was adopted as the primary procedure in 12 patients (70.6\%) and was successful in $11(91.7 \%)$. In the only failure, the sepsis recurred, and a successful advancement flap procedure was eventually performed. Five other patients (29.4\%) underwent this same procedure as a secondary procedure after an initial drainage operation. Only one was successful. In the remaining four patients, one had a recurrent abscess that required drainage while the other three patients had a tract between the internal opening and the intersphincteric incision. They subsequently underwent a drainage procedure with seton insertion and advancement flap procedures.

Conclusion: Managing DPA space sepsis via an intersphincteric approach is successful in $70.6 \%$ of patients. This single-staged technique allows for effective drainage of the sepsis and removal of the primary pathology in the intersphincteric space.

Keywords: Abscess; Treatment outcome; Anal gland; Fistula

\section{INTRODUCTION}

The principles in the management of deep postanal (DPA) space sepsis have remained consistent through the years [1-4]. These include removing any infected collection through a drainage procedure, followed by a definitive procedure to eradicate the source of

Received: November 5, 2012 - Accepted: March 22, 2013

Correspondence to: Charles B. Tsang, M.D.

Division of Colorectal Surgery, University Surgical Cluster, National University Health System, 1E Kent Ridge Road, Singapore 119228, Singapore

Tel: +65-67724235, Fax: +65-67778206

E-mail:drcharlestsang@colorectalclinic.com

This article was presented as a poster in the ASCRS Annual Meeting held in Vancouver, British Columbia, Canada from 14-18 May 2011.

(C) 2013 The Korean Society of Coloproctology

This is an open-access article distributed under the terms of the Creative Commons Attribution NonCommercial License (http://creativecommons.org/licenses/by-nc/3.0) which permits unrestricted noncommercial use, distribution, and reproduction in any medium, provided the original work is properly cited. sepsis.

Numerous surgical procedures have been described in the treatment of DPA space sepsis [5-7]. These include a posterior midline sphincterotomy, the seton technique, a fistulotomy and an advancement flap procedure. However, these patients often require multiple operations that are associated with complications such as treatment failure, recurrence and incontinence [5-7].

Following the same principles as those for the ligation of the intersphincteric fistula tract technique pioneered by Rojanasakul et al. $[8,9]$ from Thailand for the management of a transsphincteric fistula, the authors propose an intersphincteric approach to manage DPA space sepsis. This novel technique essentially allows for drainage of the abscess, removal of the source of sepsis, i.e., the anal crypt gland, and ligation and resection of the fistula tract in the intersphincteric space while preserving the integrity of the anal sphincter without dividing any muscles. The aim of this study was to review our initial surgical experience using this new technique in managing DPA space sepsis. 


\section{Coloproctology}

Managing Deep Postanal Space Sepsis via an Intersphincteric Approach: Our Early Experience

\section{METHODS}

A retrospective review of all patients who underwent this intersphincteric procedure for DPA space sepsis from February 2008 to October 2010 was performed. Only patients with abscesses and fistulas of cryptoglandular origin were included in this study. All patients underwent preoperative endoanal ultrasonography (EAUS) to confirm the presence and the extent of the pathology (Fig. 1 and 2). The study protocol was reviewed and approved by the Institutional Review Board.

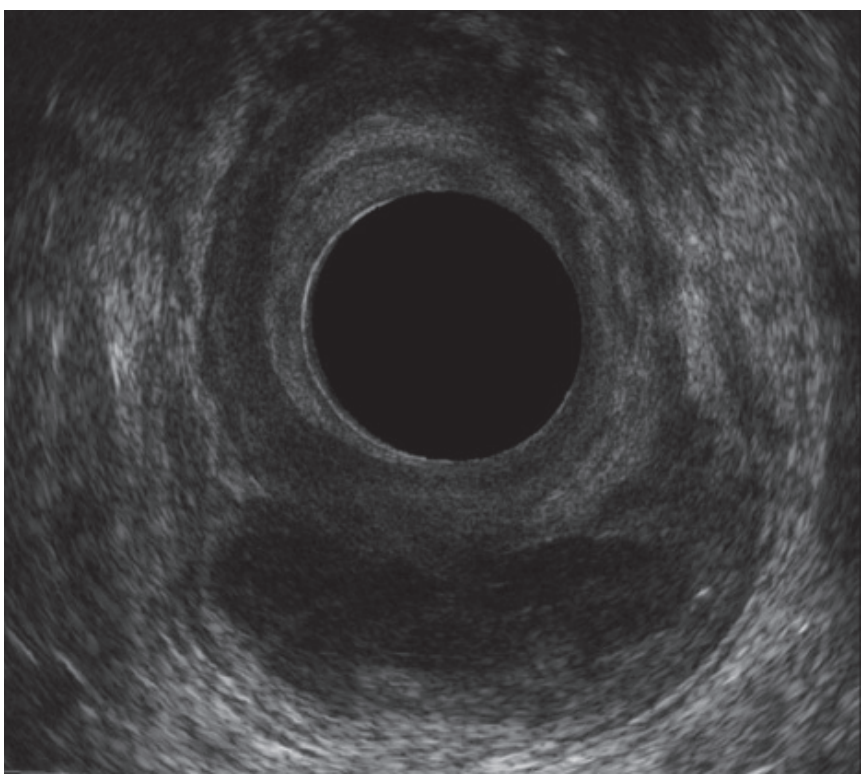

Fig. 1. Endoanal ultrasonographic image of a deep postanal space abscess (axial view).

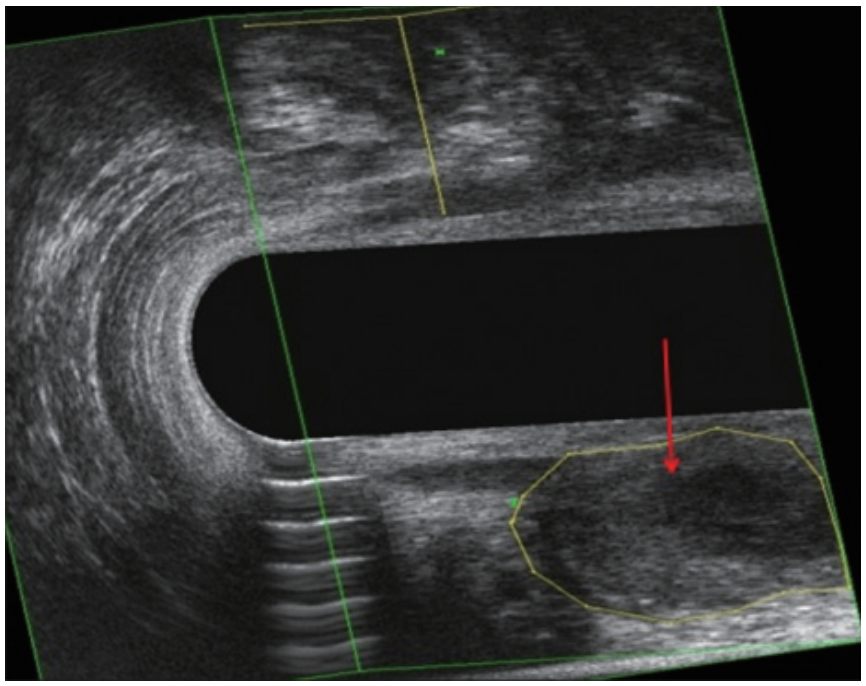

Fig. 2. Endoanal ultrasonographic image of a deep postanal space abscess (3-dimentional view).

\section{Operative technique}

Following preoperative bowel preparation using a sodium-phosphate enema, the patients were placed in the prone jack-knife position after the induction of general anaesthesia. An Eisenhammer anal retractor was first inserted into the anal canal and the intersphincteric groove was identified. A 2- to 3-cm curvilinear skin incision was made posterior to the intersphincteric groove as guided by the preoperative EAUS. A Lone Star Retractor System (Cooper Surgical, Trumbull, CT, USA) was then placed, and the incision was deepened using electrocautery. The intersphincteric space was developed in a cephalad direction, and the indurated intersphincteric tract/tissue on the lateral surface of the internal sphincter was identified (Fig. 3). Continually and superiorly along the intersphincteric plane and then over the external sphincter

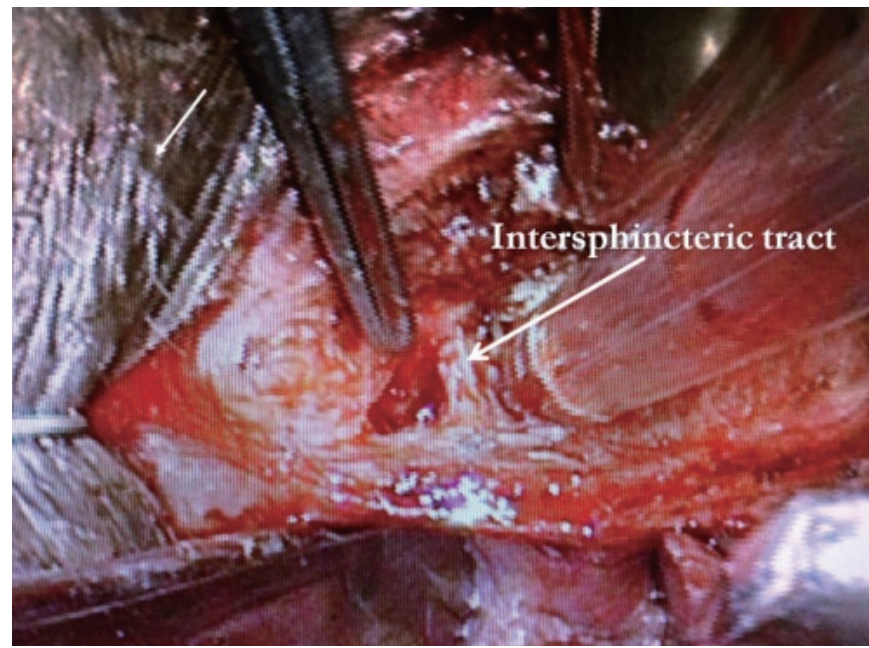

Fig. 3. Identification of the intersphincteric tract.

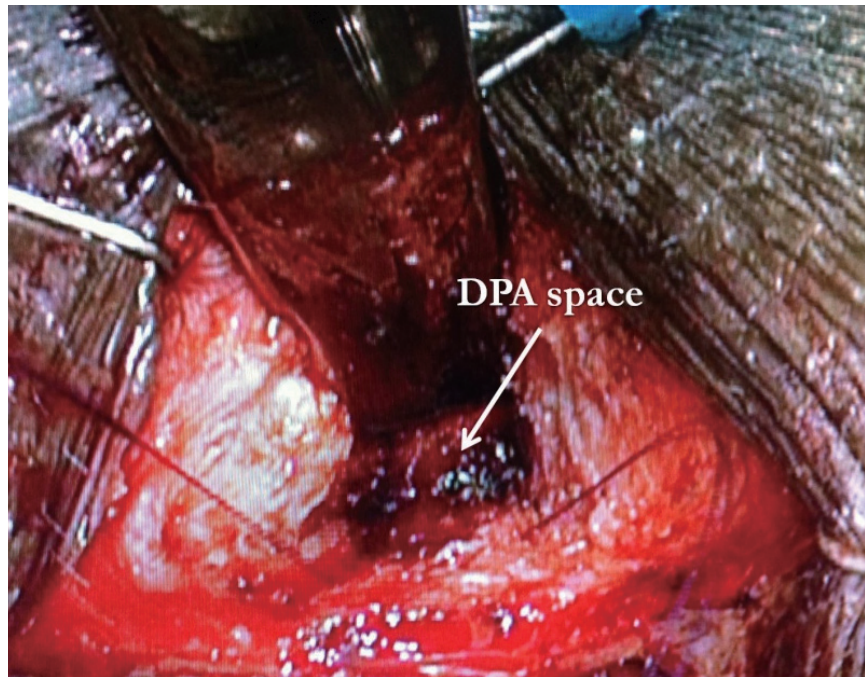

Fig. 4. Illustration of the access to the deep postanal (DPA) space through the intersphincteric incision. 
posteriorly, the DPA space was entered, allowing the abscess to be drained and the cavity to be curetted (Fig. 4). Following that, the internal opening on the surface of the internal sphincter was closed using 4/0 absorbable monofilament polydioxanone sutures.

Irrigation of the DPA cavity and its extensions was then performed before placement of a Redivac suction drain (Medinorm, Quierschied, Germany) into the DPA cavity to facilitate continual drainage. Approximation of the internal and the external sphincter muscles and the skin was performed using 4/0 polyglactin sutures. The infected tissues from the DPA space were sent for culture and sensitivity tests.

\section{Follow-up}

All patients were discharged with a one-week course of oral antibiotics (amoxycillin-clavulanate or ciprofloxacin and metronidazole) and were reviewed by the senior author in the outpatient clinic one week following surgery. The drain was removed when the drainage was deemed to be minimal. Success was defined as the absence of any recurrence and the complete healing of the intersphincteric wound. An additional course of appropriate antibiotics would be administered should the cultures reveal a multi-resistant organism.

\section{RESULTS}

Seventeen patients, with a median age of 43 years (range, 32 to 71 years) and including 16 males (94.1\%), formed the study group. All the patients presented with an abscess collection in the DPA space, which was confirmed on EAUS. In all patients, an internal opening in the posterior midline was identified, with a tract leading to the DPA space. An external opening was present in eight patients (47.1\%).

This intersphincteric approach technique was adopted as the primary procedure in twelve patients (70.6\%) (Table 1). Five of these patients had had simple incision and drainage procedures performed between 8 months and 12 years earlier. Eleven (91.7\%) had successful outcomes. The only failure $(8.3 \%)$ was a recurrence of the DPA space abscess 15 weeks after the initial procedure. That patient subsequently underwent a drainage procedure with seton placement. This was followed by a successful advancement flap procedure 6 weeks later.

The other group consisted of five patients (29.4\%) (Table 2) who had undergone this procedure only after an initial drainage operation. This was defined in our series as an operation to drain the abscess within the 6 months immediately preceding this procedure. Only two of these patients had an external opening suggestive of an underlying fistula. The median time from the previous drainage operation to this intersphincteric approach procedure was 6 weeks ( 4 to 19 weeks). The five patients returned with symptoms and signs suggestive of an underlying abscess that was concurrently drained during the intersphincteric approach procedure. For four of them $(80.0 \%)$, the procedure failed, and they required further operations. Three of them developed a tract from the internal opening to the intersphincteric incision site. Two of the three underwent successful advancement flap procedures at 4 and 10 months after the intersphincteric procedures. The third patient underwent a drainage procedure with seton insertion. $\mathrm{He}$ then refused further surgery. The last patient who experienced a failed procedure developed a unilateral ischioanal abscess six weeks postoperatively, and this necessitated a drainage procedure. Intra-operatively, the previous internal opening remained closed.

Over a median follow-up of 8 months (5 to 32 months), the

Table 1. Group of patients who underwent the intersphincteric approach operation as the primary procedure

\begin{tabular}{|c|c|c|c|c|c|c|c|c|}
\hline No. & Age (yr) & Gender & Previous surgery & $\begin{array}{l}\text { Severity of deep postanal } \\
\text { space sepsis } \\
\text { (extension, if any) }\end{array}$ & $\begin{array}{l}\text { Location of internal } \\
\text { opening/ external opening }\end{array}$ & Outcome & $\begin{array}{l}\text { Subsequent } \\
\text { procedure(s) }\end{array}$ & $\begin{array}{c}\text { Duration of } \\
\text { follow-up (mo) }\end{array}$ \\
\hline 1 & 51 & Male & & Ipsilateral & 60 o'clock / absent & Success & Nil & 7 \\
\hline 2 & 71 & Male & & Bilateral & 60 o'clock / absent & Success & Nil & 32 \\
\hline 3 & 42 & Male & & Posteriorly only & 6 0'clock / 6 o'clock & Success & Nil & 25 \\
\hline 4 & 40 & Male & & Posteriorly only & 6 0'clock / absent & Success & Nil & 5 \\
\hline 6 & 47 & Male & & Ipsilateral & 6 0'clock / 8 o'clock & Success & Nil & 6 \\
\hline 7 & 32 & Male & & Ipsilateral & 6 0'clock / 4 o'clock & Success & $\mathrm{Nil}$ & 7 \\
\hline 8 & 46 & Male & & Posteriorly only & 6 0'clock / 2 o'clock & Success & Nil & 7 \\
\hline 9 & 36 & Male & Drainage, 8 mo ago & Bilateral & 6 0'clock / absent & Success & Nil & 8 \\
\hline
\end{tabular}


Table 2. Group of patients who underwent the intersphincteric approach operation after an initial drainage procedure

\begin{tabular}{|c|c|c|c|c|c|c|c|c|}
\hline No. & $\begin{array}{l}\text { Age } \\
\text { (yr) }\end{array}$ & Gender & Previous surgery & $\begin{array}{c}\text { Severity of deep postanal } \\
\text { space sepsis } \\
\text { (extension, if any) }\end{array}$ & $\begin{array}{l}\text { Location of internal } \\
\text { opening/external opening }\end{array}$ & Outcome & $\begin{array}{l}\text { Subsequent } \\
\text { procedure(s) }\end{array}$ & $\begin{array}{c}\text { Duration of } \\
\text { follow-up (mo) }\end{array}$ \\
\hline 1 & 43 & Male & Drainage, 6 wk ago & Ipsilateral & 6 0'clock / 3 o'clock & Failed & $\begin{array}{l}\text { Drainage \& seton } 18 \text { mo later, } \\
\text { declined endorectal advancement flap }\end{array}$ & 28 \\
\hline 2 & 56 & Male & Drainage, 19 wk ago & Posteriorly only & 6 0'clock / 6 o'clock & Success & Nil & 7 \\
\hline 3 & 40 & Male & $\begin{array}{l}\text { Drainage \& seton, } \\
14 \text { wk ago }\end{array}$ & Posteriorly only & 6 0'clock / 6 o'clock & Failed & Anocutaneous flap 4 mo later & 12 \\
\hline 5 & 53 & Male & Drainage, 6 wk ago & Ipsilateral & 60 o'clock / absent & Failed & $\begin{array}{l}\text { Drainage \& seton } 3 \text { mo later, then } \\
\text { anocutaneous flap } 7 / 12 \text { later }\end{array}$ & 27 \\
\hline
\end{tabular}

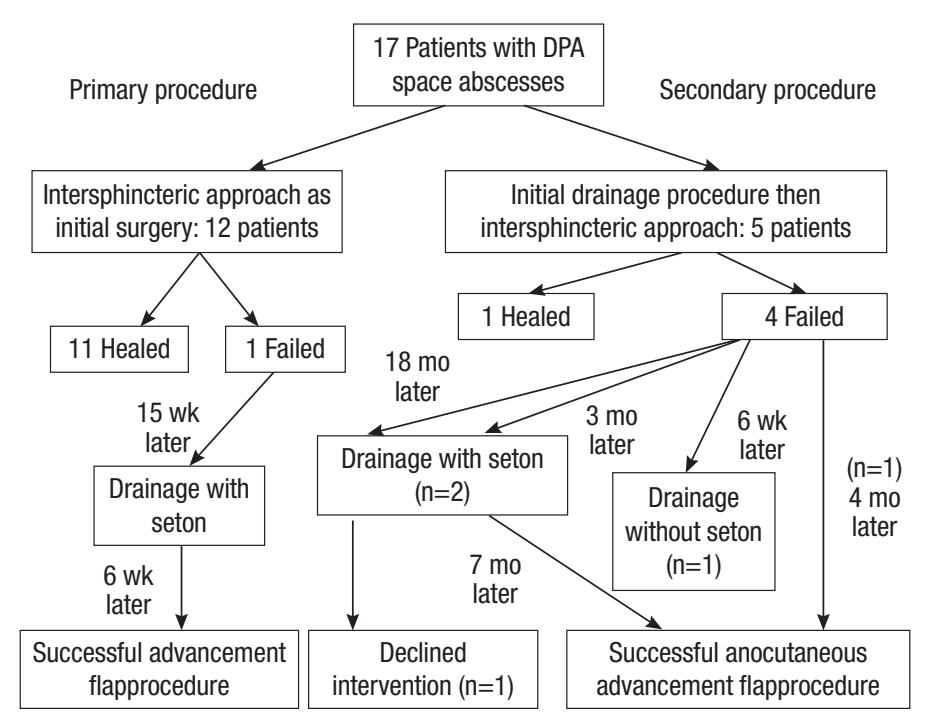

Fig. 5. Flowchart of all the patients who underwent the intersphincteric approach for a deep postanal (DPA) space abscess.

overall success rate of this intersphincteric procedure in managing DPA space sepsis was 70.6\%. A flowchart depicting the progress and the outcome for all our patients following their surgeries is shown in Fig. 5.

\section{DISCUSSION}

The management of DPA space abscesses continues to pose numerous challenges to colorectal surgeons worldwide [1-4]. Some of the most common procedures that have been described in the treatment of DPA space sepsis include a fistulotomy, a posterior midline sphincterotomy, a seton technique and an advancement flap procedure. Whilst techniques such as a fistulotomy and a posterior midline sphincterotomy and de-roofing of the abscess cavities were coupled with high success rates, surgeons are still uncomfortable with the division of a significant portion of the sphincters and the possibility of its causing incontinence in the long term $[1,6,7]$. The seton technique remains popular currently. Although the draining seton technique aims to minimize incontinence while enabling continual drainage, it is not always successful and patients are often subjected to repeated operations. On the other hand, the cutting seton technique can also result in incontinence in the long term $[1,6,10,11]$. The advancement flap procedure is usually adopted as the definitive procedure in such cases when the sepsis has been adequately drained by using a seton [11-13]. Albeit with high success rates, the technique is difficult to master.

With the aforementioned considerations in mind, the authors are proposing treating this condition via a novel approach through the intersphincteric space. To our knowledge, this technique for the management of DPA space sepsis has not been described in the literature. A success rate of $70.6 \%$ was achieved during our initial experience with this procedure.

This new approach addresses the underlying etiology of all DPA space abscesses (including bilateral horseshoe abscesses), which is the infected anal crypt gland in the posterior intersphincteric space. At the same time, adequate drainage of the DPA space can be achieved without creating lengthy incisions over the ischioanal fossae. This technique can also be successfully performed as a single-stage procedure.

In our study, the 12 patients who had had no recent drainage surgery demonstrated a higher success rate of $91.7 \%(11 / 12)$, compared to $20 \%(1 / 5)$ in the group of patients who had undergone recent prior drainage. We believe that the critical step in this technique lies in the successful identification of the intersphincteric space and the excision of the infected anal crypt gland, i.e., the intersphincteric tract. A possible explanation for this difference could be the fibrosis and the obliteration of the intersphincteric space following the resolution of the inflammation in the same area after the initial drainage procedure. This would often make any subsequent dissection in the intersphincteric space and identification and excision of the intersphincteric tract technically more difficult. However, the number of patients in our series is 
too small to make any concrete conclusions at this juncture.

Apart from the small number of patients, the retrospective nature of our series and the relatively short duration of follow-up are also limitations. There were also no confirmatory radiological investigations to confirm the resolution of the DPA space sepsis. In addition, incontinence scoring was not obtained for these patients.

When compared to the commonly-adopted techniques for DPA space sepsis, the advantages of this new technique are obvious. This technique can be performed as a single-stage procedure, with minimal morbidity and acceptable success rates. It essentially obviates the need for repeated operations over a long period of time. A prolonged period of postoperative wound care would also be unnecessary. The long-term success rates of this technique and its impact on continence will be issues that require further studies. A comparative prospective study between the various techniques advocated for DPA space sepsis would be ideal.

In conclusion, managing DPA space sepsis via an intersphincteric approach is promising and has an acceptable success rate. This single-staged technique enables effective drainage of the sepsis and removal of the primary pathology via the intersphincteric space.

\section{CONFLICT OF INTEREST}

No potential conflict of interest relevant to this article was reported.

\section{REFERENCES}

1. Pezim ME. Successful treatment of horseshoe fistula requires deroofing of deep postanal space. Am J Surg 1994;167:513-5.

2. Hamilton $\mathrm{CH}$. Anorectal problems: the deep postanal space: surgical significance in horseshoe fistula and abscess. Dis Colon
Rectum 1975;18:642-5.

3. Hanley PH. Conservative surgical correction of horseshoe abscess and fistula. Dis Colon Rectum 1965;8:364-8.

4. Hanley PH, Ray JE, Pennington EE, Grablowsky OM. Fistula-inano: a ten-year follow-up study of horseshoe-abscess fistula-inano. Dis Colon Rectum 1976;19:507-15.

5. Rosen SA, Colquhoun P, Efron J, Vernava AM 3rd, Nogueras JJ, Wexner SD, et al. Horseshoe abscesses and fistulas: how are we doing? Surg Innov 2006;13:17-21.

6. Held D, Khubchandani I, Sheets J, Stasik J, Rosen L, Riether R. Management of anorectal horseshoe abscess and fistula. Dis Colon Rectum 1986;29:793-7.

7. Inceoglu R, Gencosmanoglu R. Fistulotomy and drainage of deep postanal space abscess in the treatment of posterior horseshoe fistula. BMC Surg 2003;3:10.

8. Rojanasakul A. LIFT procedure: a simplified technique for fistulain-ano. Tech Coloproctol 2009;13:237-40.

9. Rojanasakul A, Pattanaarun J, Sahakitrungruang C, Tantiphlachiva K. Total anal sphincter saving technique for fistula-in-ano; the ligation of intersphincteric fistula tract. J Med Assoc Thai 2007;90: 581-6.

10. Garcia-Aguilar J, Belmonte C, Wong DW, Goldberg SM, Madoff $\mathrm{RD}$. Cutting seton versus two-stage seton fistulotomy in the surgical management of high anal fistula. Br J Surg 1998;85:243-5.

11. Browder LK, Sweet S, Kaiser AM. Modified Hanley procedure for management of complex horseshoe fistulae. Tech Coloproctol 2009;13:301-6.

12. Jarrar A, Church J. Advancement flap repair: a good option for complex anorectal fistulas. Dis Colon Rectum 2011;54:1537-41.

13. Dubsky PC, Stift A, Friedl J, Teleky B, Herbst F. Endorectal advancement flaps in the treatment of high anal fistula of cryptoglandular origin: full-thickness vs. mucosal-rectum flaps. Dis Colon Rectum 2008;51:852-7. 